\title{
LA-UR- $00-5268$
}

Approved forpublic release; distribution is unlimited.

\author{
Title: REVIEW AND COMPARISONS OF D/R MODELS OF \\ EQUILIBRIUM ADSORPTION OF BINARY MIXTURES OF \\ ORGANIC VAPORS ON ACTIVATED CARBONS
}

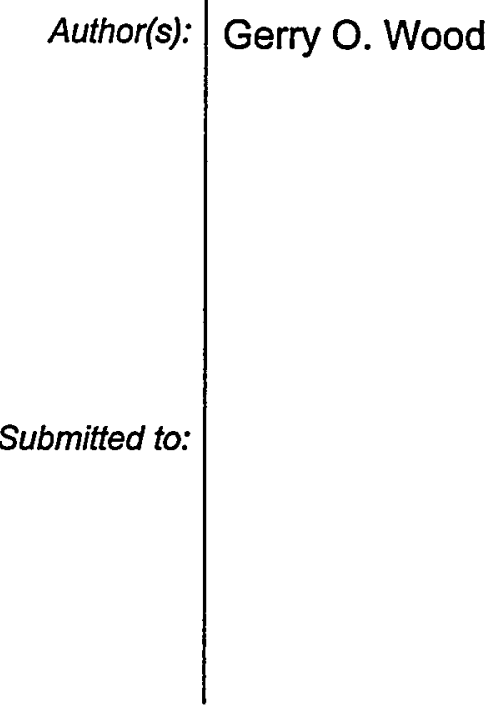

\section{Los Alamos} NATIONAL LABORATORY

Los Alamos National Laboratory, an affirmative action/equal opportunity employer, is operated by the University of California for the U.S. Department of Energy under contractW-7405-ENG-36. By acceptance of this article, the publisher recognizes that the U.S. Govemment retains a nonexclusive, royalty-free license to publish or reproduce the published form of this contribution, or to allow others to do so, for U.S. Government purposes. Los Alamos National Laboratory requests that the publisher identify this article as work performed under the auspices of the U.S. Department of Energy. Los Alamos National Laboratory strongly supports academic freedom and a researcher's right to publish; as an institution, however, the Laboratory does not endorse the viewpoint of a publication or guarantee its technical correctness. 


\section{DISCLAIMER}

This report was prepared as an account of work sponsored by an agency of the United States Government. Neither the United States Government nor any agency thereof, nor any of their employees, make any warranty, express or implied, or assumes any legal liability or responsibility for the accuracy, completeness, or usefulness of any information, apparatus, product, or process disclosed, or represents that its use would not infringe privately owned rights. Reference herein to any specific commercial product, process, or service by trade name, trademark, manufacturer, or otherwise does not necessarily constitute or imply its endorsement, recommendation, or favoring by the United States Government or any agency thereof. The views and opinions of authors expressed herein do not necessarily state or reflect those of the United States Government or any agency thereof. 


\section{DISCLAIMER}

Portions of this document may be illegible in electronic image products. Images are produced from the best available original document. 


\title{
Review and Comparisons of $D / R$ Models of Equilibrium Adsorption \\ of Binary Mixtures of Organic Vapors on Activated Carbons
}

\author{
G.O. Wood* \\ Los Alamos National Laboratory, Mail Stop K-486, Los Alamos, NM 87545 \\ *E-mail: gerry@lanl.gov; Tel: (505) 667-9824; Fax: (505) 665-2192
}

\begin{abstract}
Published models and options for predicting equilibrium adsorption capacities of multicomponent mixtures using single component Dubinin/Radushkevich isotherm equations and parameters were reviewed. They were then tested for abilities to predict total and component capacities reported for 93 binary adsorbed mixtures. The best model for calculating molar distributions was the Ideal Adsorbed Solution Theory (IAST), which balances spreading pressures. Combined with the IAST, total and component capacities were best calculated using either the Lewis or original Bering equation with the Ideal Adsorbed Solution (Raoult's Law)
\end{abstract} assumption.

Keywords: A. Activated carbon; C. Adsorption, modelling; D. Phase equilibria

PECEIVE筑 DEC 132000 OSTI

\section{Introduction}

The impetus for this review and testing of multicomponent vapor adsorption models was to choose the best one as a basis for developing a model of adsorption onto activated carbon of vapors from mixtures in flowing air. One application goal is the prediction of service lives (breakthrough times) of organic vapor air-purifying respirator cartridges. In searching and 
reviewing the diverse and scattered literature we recognized the need to summarize proposed models and publish them together in one place. Since they have been validated based on different and limited data sets (often for light gases, not vapors of condensable chemicals), we also saw a need to compare models with a common set of multivapor data.

The bases for multicomponent adsorption models are always the adsorption isotherm equations and parameters of individual components. Many of the isotherm equations proposed for describing adsorption isotherm data (Freundlich, Langmuir, Langmuir/Freundlich, Dubinin/Radushkevich, Polanyi, Kisarov, Vacancy Solution Model, and Johns) have been reviewed for multicomponent applicability [1]. The Dubinin/Radushkevich adsorption isotherm equation [2] is the most versatile, proven, and useful model for predicting, as well as describing, equilibrium adsorption capacities of organic vapors on ordinary commercial activated carbons [1,3]. For specialized carbons the more general Dubinin/Astakhov equation [4] with an additional parameter can be used. These Dubinin equations have the advantages of including: a) carbon property parameters, $b$ ) vapor property parameters, and c) temperature. Only the Kisarov equation [5] can also claim this, but it has been much less proven with data and was less successful in the preliminary studies for mixtures [1]. Other isotherm equations, particularly the Freundlich Equation, are useful for correlating experimental adsorption capacities, but have had little success in predicting capacities for unmeasured vapors.

Therefore, only mixture models based on the Dubinin/Radushkevich (D/R) adsorption isotherm equation were included in this review and study. The single vapor $D / R$ equation for $n$ moles adsorbed (e.g., $\mathrm{mol} / \mathrm{g}$ ) in equilibrium with its vapor pressure (or concentration in any consistent units) $\mathrm{p}$ can be expressed as: 


$$
\mathrm{n}=\frac{\mathrm{W}_{\mathrm{o}}}{\mathrm{V}_{\mathrm{m}}{ }^{0}} \exp \left[-\left(\frac{\mathrm{RT}}{\beta \mathrm{E}_{\mathrm{o}}}\right)^{2}\left\{\ln \left(\mathrm{p}_{\mathrm{sat}} / \mathrm{p}\right\}^{2}\right]\right.
$$

where $\mathrm{W}_{0}\left(\mathrm{~cm}^{3} / \mathrm{g}\right)$ is the micropore volume of the adsorbent and $E_{0}(\mathrm{~kJ} / \mathrm{mol})$ is its reference adsorption energy; $\mathrm{V}_{\mathrm{m}}{ }^{0}\left(\mathrm{~cm}^{3} / \mathrm{mol}\right)$ is the liquid molar volume of the adsorbate, $\beta$ is its affinity coefficient (relative to the reference), and $\mathrm{p}_{\text {sat }}$ is the vapor pressure of its unadsorbed bulk form at temperature $T$. One of the best features of the $D / R$ equation is the inclusion of the affinity coefficient, which allows the application of the parameters of micropore volume and reference adsorption energy measured with one vapor to predict adsorption capacities of other vapors. A thorough review with compilations and correlations of affinity coefficients has been published [6], which makes single vapor isotherms easily predictable, even for water vapor. Benzene is usually chosen as the reference vapor $(\beta=1.0)$.

\section{Background}

Mixed D/R Isotherm Equations: The simplest extensions of the D/R equation to mixtures of miscible components involve mole fraction $\left(\mathrm{x}_{\mathrm{i}}\right)$ weighting of affinity coefficient $\left(\beta_{\mathrm{i}}\right)$, partial liquid molar volume $\left(\mathrm{V}_{\mathrm{mi}}\right)$, and adsorption potential $\left(\varepsilon_{\mathrm{i}}=\mathrm{RT} \ln \left[\mathrm{p}_{\mathrm{si}} / \mathrm{p}_{\mathrm{i}}\right]\right)$ parameters of the components $\mathrm{i}$ to calculate total molar capacity, $\mathrm{n}_{\mathrm{T}}$, for the mixture. This was first proposed by Bering et al. [7]:

$$
\mathrm{n}_{\mathrm{T}}=\frac{\mathrm{W}_{0}}{\mathrm{~V}_{\mathrm{mT}}} \exp \left[-\left(\frac{\varepsilon_{\mathrm{T}}}{\beta_{\mathrm{T}} \mathrm{E}_{\mathrm{o}}}\right)^{2}\right]
$$

where $\beta_{\mathrm{T}}=\Sigma \mathrm{x}_{\mathrm{i}} \beta_{\mathrm{i}}$

$$
\begin{aligned}
& \mathrm{V}_{\mathrm{mT}}=\Sigma \mathrm{x}_{\mathrm{i}} \mathrm{V}_{\mathrm{mi}} \\
& \varepsilon_{\mathrm{T}}=\mathrm{RT} \Sigma \mathrm{x}_{\mathrm{i}} \ln \left(\mathrm{p}_{\mathrm{si}} / \mathrm{p}_{\mathrm{i}}\right)
\end{aligned}
$$

This equation will be called the Bering1 model. 
Bering et al.[7] left to "experience" which to choose for the standard reference state of a mixture and the corresponding standard pressures $\mathrm{p}_{\mathrm{si}}$ of components $\mathrm{i}$ in the adsorbed mixture: "...the state of a solution whose composition is equal to the composition of the adsorbed phase or the state of a solution existing in equilibrium with vapor whose composition is equal to the composition of the equilibrium vapor above the adsorption phase,...." They suggested that the partial molar volumes be determined "from the phase diagram of the volume solution,...." Such selections of standard states and molar volumes are not practical for a widely applicable predictive model for mixtures, since the required mixture phase diagrams usually do not exist.

Bering et al. [7] also proposed an alternative in which the relative partial pressures of the components of the mixture are set equal to the ratio of the sum of the pressures of the components to the sum of the standard state pressures. For a binary mixture this is:

$$
\frac{p_{s 12}}{p_{12}}=\frac{p_{s 1}+p_{s 2}}{p_{1}+p_{2}}
$$

The corresponding $\mathrm{D} / \mathrm{R}$ equation for a multicomponent mixture is:

$$
\mathrm{n}_{\mathrm{T}}=\frac{\mathrm{W}_{\mathrm{o}}}{\mathrm{V}_{\mathrm{mT}}} \exp \left[-\left(\frac{\mathrm{RT}}{\beta_{\mathrm{T}} \mathrm{E}_{\mathrm{o}}}\right)^{2}\left(\ln \left(\frac{\Sigma \mathrm{p}_{\mathrm{si}}}{\Sigma \mathrm{p}_{\mathrm{i}}}\right)\right)^{2}\right]
$$

This equation will be called the Bering2 model. They found that Equations (4) well described ethyl chloride-diethyl ether and diethyl ether-chloroform mixtures adsorbed on an activated carbon. Phase diagrams of liquid mixtures were used to get standard state pressures $\mathrm{p}_{\mathrm{si}}$ of the components. Under certain conditions Equations (2) and (4) were shown to be equivalent [8]. Another approach has been taken in weighting adsorption potentials. Xie et al. [9] used:

$$
\varepsilon_{\mathrm{T}}=\Sigma \mathrm{x}_{\mathrm{i}} \ln \left(\gamma_{\mathrm{i}} \mathrm{x}_{\mathrm{i}} \mathrm{p}_{\mathrm{sati}}{ }^{\circ} / \mathrm{p}_{\mathrm{i}}\right)
$$


where $\gamma_{i}$ are activity coefficients, which in their applications for three binary mixtures (benzenehexane, benzene-pentane, and hexane-pentane) on two carbons were apparently taken as unity. They did not use the $D / R$ equation, but a similar one with the same weighted terms and an additional empirical parameter for micropore size distribution homogeneity. Using this weighting approach with the Bering1 Equation (2) gives:

$$
\mathrm{n}_{\mathrm{T}}=\frac{\mathrm{W}_{\mathrm{o}}}{\mathrm{V}_{\mathrm{mT}}} \exp \left[-\left(\frac{\mathrm{RT}}{\mathrm{E}_{\mathrm{o}}}\right)^{2}\left\{\frac{\Sigma \mathrm{x}_{\mathrm{i}} \ln \left(\mathrm{x}_{\mathrm{i}} \mathrm{p}_{\mathrm{sati}}{ }^{\mathrm{o}} / \mathrm{p}_{\mathrm{i}}\right)}{\beta_{\mathrm{T}}}\right\}^{2}\right]
$$

Taking the standard reference component pressures to be $x_{i} p_{s a t i}{ }^{\circ}$ (superscript $o$ indicates pure component) is the same as assuming Raoult's Law and an ideal adsorbed solution (see later discussion). Therefore, Equation (6) will be referred to as the Bering1-IAS model and option. Mixture D/R isotherm equations such as Equations (2), (4), and (6) give only the total moles of mixture adsorbed. The component distributions (e.g., as moles $n_{i}$ or mole fractions $x_{i}$ ) must be known or determined independently by another assumption and equation.

Lewis Equation: The equation most often used to obtain moles of mixture components when total molar capacity is known or calculated is:

$$
\Sigma \frac{\mathrm{n}_{\mathrm{i}}}{\mathrm{n}_{\mathrm{i}}^{\circ}}=1
$$

where $n_{i}{ }^{\circ}$ are the reference adsorbed molar capacities of the pure components and $n_{i}$ are the molar capacities of the components in the adsorbed mixture. It is based on an empirical correlation obtained for adsorption from constant total pressure mixtures of hydrocarbon gases by Lewis et al. [10]. The Lewis Equation for a binary mixture in terms of mole fractions and total molar capacity $(\mathrm{mol} / \mathrm{g})$ is: 


$$
\frac{1}{\mathrm{n}_{\mathrm{T}}}=\frac{\mathrm{x}_{1}}{\mathrm{n}_{1}{ }^{\mathrm{o}}}+\frac{\mathrm{x}_{2}}{\mathrm{n}_{2}{ }^{0}}
$$

Xie et al. [9] proposed a volumetric form of the Lewis Equation for non-ideal mixtures:

$$
\Sigma \frac{V_{m i} n_{i}}{V_{m i}{ }^{0} n_{i}^{0}}=1
$$

Partial molar volumes $\mathrm{V}_{\mathrm{mi}}$ for each mixture composition must be obtained from independent mixing data. The Lewis Equation can also be used to calculate total molar capacity when the mole fractions are determined by another method (see below).

Since the original Lewis correlation was obtained from mixtures at constant total pressure, the reference adsorbed molar capacities $n_{i}{ }^{0}$ should be calculated at $p_{i}^{0}=\Sigma p_{j}$, the total pressure of the components, rather than at $p_{i}$. However, Lavanchy et al. [11] and Sundaram [12] both successfully applied the Lewis Equation assuming Raoult's Law for an ideal solution for which $\mathrm{p}_{i}{ }^{0}=\mathrm{p}_{\mathrm{i}} / \mathrm{x}_{\mathrm{i}}$. For these cases the proper $\mathrm{D} / \mathrm{R}$ standard reference pressure is $\mathrm{p}_{\mathrm{si}}=\mathrm{p}_{\mathrm{sati}}{ }^{0}$, the saturation vapor pressure of the pure component $i$.

Polanyi Adsorption Potential Theory: One of the most popular theories relating adsorption of vapors of single pure chemicals is the Polanyi Theory [13]. Lewis et al. [10] and Grant and Manes [14] have developed it for mixtures. The latter assumed: a) a liquid-like adsorbate mixture in which the adsorption potential of each pure adsorbed component is determined by the total adsorbate volume of the mixture, b) Raoult's Law as the relationship between the partial pressure of each component and its adsorbate mole fraction, and c) the adsorbate volumes are additive. According to the Polanyi Theory all characteristic curves (adsorption capacities vs. adsorption potentials) on a given adsorbent are superimposable to form a single curve by using correlating divisors for the adsorption potentials. This correlating divisor can be a) molar volume calculated at the boiling point corresponding to adsorption pressure [10], 
b) normal boiling point molar volume [14], or, more generally, c) the affinity coefficient $\beta$ of

Dubinin $[2,4]$. This theory for mixtures states that:

$$
\left(R T / \beta_{1}\right) \ln \left(x_{1} f_{1 s} / f_{1}\right)=\left(R T / \beta_{2}\right) \ln \left(x_{2} f_{2 s} / f_{2}\right)=\text { etc. }
$$

Fugacities $f_{i}$ (and $f_{i s}$ for saturated vapors) used by Grant and Manes for high-pressure gases can be replaced with partial (and saturated vapor) pressures $\mathrm{p}_{\mathrm{i}}$ or concentrations $\mathrm{C}_{\mathrm{i}}$ at normal atmospheric conditions.

Grant and Manes [14] used the additivity of molar volumes:

$$
\mathrm{V}_{\mathrm{T}}=\mathrm{n}_{\mathrm{T}} \Sigma \mathrm{x}_{\mathrm{i}} \mathrm{V}_{\mathrm{mi}}
$$

and the sum of mole fractions $x_{i}$ in the adsorbate equal to unity to calculate the numbers of moles of each component adsorbed. However, this assumption of additivity is not a necessary part of the Polanyi mixture theory. Mixture isotherm equations, the Lewis Equation, Molar Proportionality, or any other way of calculating or measuring total adsorbed molar capacity can be combined with the mole fractions obtained from Equation (10) to get molar capacities of mixture components.

Ideal Adsorbed Solution Theory (IAST): Myers and Prausnitz [15] are credited with the thermodynamically consistent Ideal Adsorption Solution Theory, sometimes called the MyersPrausnitz theory. They assumed Raoult's Law and the concept of equality of spreading pressures $\Pi_{i}$ for each component:

$$
\Pi_{i}=\frac{R T}{A} \int_{0}^{p_{i}{ }^{0}} \frac{n_{i}{ }^{0}}{p_{i}} d p_{i}
$$

where $n_{i}^{0}$ is the number of moles of pure component $i$ in the adsorbed phase obtained from a pure component isotherm for a vapor pressure $\mathrm{p}_{\mathrm{i}}$. The value of $\mathrm{p}_{\mathrm{i}}{ }^{0}$ is that corresponding to the spreading pressure. $A$ is the specific area of the sorbent. Grant and Manes [14] stated that their 
adsorption theory for mixtures and the IAST are practically equivalent if the correlating divisor is molar volume.

A major difficulty with the IAST model is the requirement that the adsorption isotherms (actually, the $n_{i} / p_{i}$ ratios as functions of $p_{i}$ ) be accurately defined to zero pressure and capacity, so that they can be integrated. Some [1] have used Freundlich and other isotherm equations with this property or have fit the lower coverage portion of experimental or theoretical isotherms with empirical equations that can be integrated analytically. Sundaram [12] truncated a logarithmic expansion of the inverted D/R Equation (1) to get the Henry's Law limit and apply the IAST. Alternately, Grant and Manes [14] pointed out that the integration difficulties for the IAST could be overcome by using any Polanyi-type correlation. Subsequently, Lavanchy et al. [11] derived analytical solutions for the integrations of the Dubinin/Radushkevich and Dubinin/Astakhov equations to calculate spreading pressures. Their D/R-Ideal Adsorbed Solution equation for spreading pressure is:

$$
\Pi_{i}=\left(\frac{W_{o} \beta_{i} E_{o} \sqrt{\pi}}{2 V_{m i} R T}\right)\left(1-\operatorname{erf}\left[\left(\frac{R T}{\beta_{i} E_{o}}\right) \ln \left(\frac{x_{i} p_{s a t i}{ }^{o}}{p_{i}}\right)\right]\right)
$$

where erf is the classical error function, which can be approximated [16] by the series:

$$
\operatorname{erf}(x)=\frac{2}{\sqrt{\pi}}\left(x-\frac{x^{3}}{3}+\frac{x^{5}}{10}-\frac{x^{7}}{42}+\frac{x^{9}}{216}-\ldots\right)
$$

(Note: The negative sign before the erf is incorrect in Equation (12) of Reference 11, but correct in the Appendix derivation.) In applying this model, spreading pressures for the components are balanced by adjusting the mole fractions, which must add up to unity. The common factor ( $\mathrm{W}_{0}$ $\left.E_{0} \sqrt{ } \pi / 2 R T\right)$ is eliminated in setting the spreading pressures equal to one another. 
This Myers/Prausnitz-Dubinin (or IAST-D/R) theory has the added advantage of not requiring the reference pure vapor isotherm to be at the same temperature as the mixture. It was found to work well with miscible mixtures of chlorobenzene/carbon tetrachloride [11], 1,2dichloroethane/benzene [17], and the ternary mixture carbon tetrachloride/chlorobenzene/2chloropropane [18]. Multicomponent breakthrough times and curves, as well as adsorbed capacities at equilibrium, were successfully predicted.

A volumetric form of the IAST can be called the Volumetric Adsorbed Solution Theory (VAST). Since molecules of mixture components occupy different volumes, their evaporation rates and corresponding pressures should be proportional to volume fractions, not mole fractions (all intermolecular interactions being equal). Also, since activated carbon is a volume filling sorbent, we should have a "filling pressure", rather than a spreading pressure. Equation (13), then, can be used to equate filling pressures and calculate volume fractions, which can be converted to mole fractions by knowing partial molar volumes in the corresponding mixture.

As with the Polanyi Adsorbed Potential Theory, which also gives adsorbed mixture component distributions, the IAST and VAST require a second equation to determine total and component adsorbed capacities.

Exclusion Theories: Models based on exclusion assume that each adsorbate in a mixture reduces the sorbent available for adsorbing the other(s). In Molar Exclusion the adsorbates reduce the number of surface sites or area; in Volume Exclusion they reduce adsorption volume. The adsorbates are still considered independent and existing as if they are in the pure state; only the area or volume to be filled is less for each because of the presence of the other. Doong and Yang [19] proposed a Volume Exclusion Model for the D/R equation, such that for component 1 of a binary mixture: 


$$
V_{1}=\left(W_{o}-V_{2}\right) \exp \left[-\left(\frac{R T}{\beta_{1} E_{0}} \ln \frac{p_{s 1}}{p_{1}}\right)^{2}\right]
$$

where $V_{1}$ and $V_{2}$ are the micropore volumes occupied by adsorbed mixture components 1 and 2 from the total micropore volume $\mathrm{W}_{0}$. If the $\mathrm{D} / \mathrm{R}$ isotherms for the pure components show significantly different micropore volumes, $\mathrm{W}_{\mathrm{ol}}$ and $\mathrm{W}_{02}$, these can be used. This and other exclusions models have been used for immiscible water-single organic vapor mixtures $[18,20-$ 21]. Benefits of the Doong/Yang simple volume exclusion model include: a) soluble by simple matrix solutions without the need for iteration, even for multiple components, and b) yielding both distributions and quantities of adsorbed mixture components without a second equation.

Proportionality Theories: The simplest model for predicting adsorption capacities of mixtures from known distributions (or distributions from total binary mixture capacity) is the Molar Proportionality Model (or Method). It incorporates the assumption that the amounts adsorbed from a vapor mixture are proportional by adsorbate mole fractions to the amounts $n_{i}^{0}$ that would have been adsorbed from a pure vapor at the same partial vapor pressure (or concentration). In other words, the different components do not interact except to "deny" adsorption to one another. This assumes a limited number of moles (adsorption sites or surface area) can be covered (the Langmuir isotherm assumption). For a binary vapor mixture (two vapors excluding air components) the total $n_{T}$ and individual amounts (e.g., mol/g) $n_{i}$ adsorbed according to Molar Proportionality is:

$$
\mathrm{n}_{\mathrm{T}}=\mathrm{x}_{1} \mathrm{n}_{1}{ }^{\circ}+\mathrm{x}_{2} \mathrm{n}_{2}{ }^{\circ}
$$

This can easily be extended to any number of vapor components. Similarly, Volume Proportionality states:

$$
\mathrm{V}_{\mathrm{T}}=\mathrm{z}_{1} \mathrm{~V}_{1}{ }^{0}+\mathrm{z}_{2} \mathrm{~V}_{2}{ }^{\circ}
$$


Any single-vapor isotherm, including the $\mathrm{D} / \mathrm{R}$, can be used to calculate the pure vapor adsorption capacities $n_{i}{ }^{\circ}$ or volumes $V_{i}{ }^{\circ}$. For example, Jonas et al. [22] used the $D / R$ isotherm with carbon tetrachloride as the reference compound to predict individual and total adsorption volumes (and corresponding gravimetric capacities in $\mathrm{g} / \mathrm{g}$ carbon) from gas phase (not adsorbed phase) mole fractions by the Molar Proportionality Method. They found fair agreement ( -10 to $+20 \%$ individual deviations) with experimental kinetic capacities obtained from slopes of plots of $1 \%$ breakthrough times vs. carbon bed weights.

Standard State Options: The Lewis, Proportionality, and Exclusion Models are all interpolations between capacities of the pure components. The pressures $p_{i}{ }^{\circ}$ and/or reference standard pressures $\mathrm{p}_{s i}{ }^{0}$ at which these pure component capacities $\mathrm{n}_{\mathrm{i}}{ }^{0}$ are to be calculated by Equation (1) is up for discussion. The first option is the Single Vapor Isotherm (SVI), where $\mathrm{p}_{i}{ }^{\circ}$ $=p_{i}$, the partial vapor pressure of component $i$ in equilibrium with the mixture, and $p_{s i}{ }^{\circ}=p_{s a t i}{ }^{\circ}$, the saturation vapor pressure of pure $i$. The second is the Ideal Adsorbed Solution (IAS) assumption, where $\mathrm{p}_{i}{ }^{0}=\mathrm{x}_{\mathrm{i}} / \mathrm{p}_{\mathrm{i}}$ or $\mathrm{p}_{s i}{ }^{0}=\mathrm{x}_{\mathrm{i}} \mathrm{p}_{\text {sati }}{ }^{0}$ (not both). Similarly, the third is the Ideal Volumetric Solution (IVS), where $\mathrm{p}_{\mathrm{i}}{ }^{\mathrm{o}}=\mathrm{z}_{\mathrm{i}} / \mathrm{p}_{\mathrm{i}}$ for volume fractions $\mathrm{z}_{\mathrm{i}}$. From the Lewis correlation we also have the possibility that the reference capacities $n_{i}^{0}$ should be calculated at the total pressure, so that $\mathrm{p}_{\mathrm{i}}{ }^{\mathrm{o}}=\Sigma \mathrm{p}_{\mathrm{i}}$. In this paper we will explore these options with the abovementioned models.

\section{Comparisons}

Database Selection: Criteria for selecting mixture equilibrium adsorption data for testing of predictive models required listings of: a) D/R parameters of the pure components (or data from which they could be derived); b) vapor phase pressures of components in adsorbed mixtures; c) adsorbed phase capacities and distributions; d) information on conditions, such as 
temperature; and e) an activated carbonaceous sorbent. Four sources of data meeting these criteria were selected: Lavanchy et al. [11] published such data for 20 binary mixtures of chlorobenzene and carbon tetrachloride on an activated carbon at $298^{\circ} \mathrm{K}$. Stoeckli et al. [21] tabulated data for 18 benzene and 1,2-dichloroethane mixtures on the same carbon at $293{ }^{\circ} \mathrm{K}$. Xie et al. [9] published 42 data for three binary mixtures (benzene-hexane, benzene-pentane, and hexane-pentane) on an activated carbon and a carbon molecular sieve. Hoppe and Worch [26] published gas phase pressures and adsorbed phase capacities for 13 mixtures of benzene and isopropanol at $303{ }^{\circ} \mathrm{K}$. Although the latter did not give the $\mathrm{D} / \mathrm{R}$ parameters for the pure components, they did list calculated pure component spreading pressures/RT for vapor pressures $400-4800 \mathrm{~Pa}$. From the benzene spreading pressures and Equation (13) we calculated a best-fit reference adsorption potential of $E_{0}=10.29 \mathrm{~kJ} / \mathrm{mol}$ and micropore volume of $\mathrm{W}_{0}=0.517 \mathrm{~cm}^{3} / \mathrm{g}$. This gave a total of 93 binary mixtures to study. Table 1 lists the mixtures and $D / R$ parameters used for model comparisons. Affinity coefficients were calculated from molecular parachors.[6] Component Molar Volumes: In applying the models discussed above a question is what to use for component molar volumes $\mathrm{V}_{\mathrm{mi}}$ in adsorbed mixtures. Data on volume changes upon mixing vs. mixture composition are necessary for exact values; however, they are seldom available. On the other hand, molar volumes of pure liquids are readily calculated from liquid densities $d_{L}$ and molecular weights $M_{w}$ as $V_{m i}{ }^{0}=M_{w} / d_{L}$. Doong and Yang reviewed other equations for estimating molar volumes above normal boiling points [19]. Since one goal of our work is to predict adsorption capacities of components of a wide variety of liquid mixtures using a minimum amount of input data, which must be readily available, in this paper we choose to use pure liquid molar volumes $\left(20-25^{\circ} \mathrm{C}\right)$, even for components of adsorbed mixtures. 


\section{Results and Analyses}

Total Capacity Calculation Comparisons: The first test of the models discussed above with the options and data discussed above was how well their calculated total adsorbed mixture capacities compared with reported total capacities. Calculations were done for each of the 21 models and options listed in Table 2 and each of the 93 mixtures. Average and Standard Deviations from the experimental values are listed in Table 2; these represent measures of accuracy and precision, respectively.

Table 2 shows that the best (and equivalent) precisions of the model predictions were obtained for the Volume Proportionality, Molar Proportionality, Lewis, and Bering1 models with the Ideal Adsorbed Solution and Ideal Volumetric Solution options. Of these, the Bering1 mixture isotherm Equation (2) with the Ideal Volumetric Solution option $\left[\varepsilon_{T}=R T \sum z_{i} \ln \left(z_{i} p_{\text {sati }}{ }^{\circ}\right.\right.$ $\left.\left./ \mathrm{p}_{\mathrm{i}}\right)\right]$ had the best average accuracy. The Single Vapor Isotherm option $\left[\left(\varepsilon_{\mathrm{T}}=\mathrm{RT} \sum \mathrm{z}_{\mathrm{i}} \ln \left(\mathrm{p}_{\text {sati }}{ }^{0} / \mathrm{p}_{\mathrm{i}}\right)\right]\right.$ produced worse precisions and accuracies in these four models.

The Volume and Molar Exclusion models' predictions were significantly worse than those of the four best, yielding results equivalent to one another due to the assumption that molar volumes were the same in mixtures as in the pure states. Bering2 model predictions were significantly worse that those for the original Bering1 model.

Mole Fraction (Distribution) Models: The second test was of those models that can calculate distributions of adsorbed mixture components, in some cases starting with calculated or experimentally known total adsorbed molar capacities. Table 3 lists these models with options and resulting measures of accuracy and precision in applying them to data. It also lists the numbers of the 93 binary mixtures for which we were able to calculate mole fractions between 0 and 1. Only results for one component of each binary mixture were used for these measures, 
since the same results would be obtained for the other of each pair. To avoid the effect of which component was chosen from each binary mixture, we averaged the absolute values of model residuals (calculated minus experimental mole fraction for one of the components).

Table 3 shows that only four of these models were able to calculate molar distributions for all 93 mixtures: IAST, VAST, Polanyi, and Volume Exclusion-SVI. Of these, the best accuracy and precision were found for the IAST and the worst for Volume Exclusion-SVI; for VAST and Polanyi they were intermediate and very similar. The Lewis and Molar Proportionality models' calculated mole fractions are very sensitive to the values of total and reference moles input, which explains their poor performances.

One other option that was tried with the IAST and Polanyi models was mole fraction weighting of the affinity coefficient: $\beta_{i}=\Sigma x_{j} \beta_{j}(j$ includes $i)$. This produced much worse accuracy and precision measures than using individual pure component $\beta_{i}$.

Combined Equation Models: The third test was to calculate both experimental distributions and experimental total capacities by combining two equation models: a) IAST, VAST, and Polanyi models were used to calculate the mole fractions of binary components; $b$ ) then the equations and options listed in the first column of Table 4 were used to calculate total and component adsorbed capacities. The latter were then compared with reported experimental values. Table 4 shows measures of accuracy (average deviations from experimental values) and precision (standard deviations).

Table 4 shows that the two models with the best (and same) combination of accuracy and precision measures were the IAST-Lewis-IAS and IAST-Bering1-IAS combinations. The Polanyi model usually had better average accuracy, but worse precision. The Ideal Volumetric 
Solution assumption gave no better (often worse) results than the Ideal (Molar) Adsorbed Solution assumption. Likewise, VAST was no improvement over IAST.

Figure 1 shows a comparison of component capacities for both components of the 93 binary mixtures calculated by the IAST-Bering1-IAS combination model with experimental values. The largest positive deviations were obtained with carbon tetrachloride and isopropanol. Deviations include both experimental and model errors.

\section{Conclusions and Discussion}

We conclude from this study that the best model for calculating equilibrium molar distributions of components of adsorbed binary mixtures of organic compounds using known single-component Dubinin/Radushkevich isotherm parameters is the Ideal Adsorbed Solution Theory. An analytical solution (Equation 13) for the necessary isotherm integrations (Equation 12) avoids the problem of no Henry's Law limit. The error function (erf) in this solution can be calculated by a series expansion. This IAST-D/R model can be extended to multiple components; however, an iterative solution (easily done by computer) is required.

A second equation is needed with the IAST-D/R to calculate total and component adsorbed capacities. The best ones were found to be the Lewis (Equation 7) and the Bering1 (Equation 2) with the Ideal Adsorbed Solution assumption, $\mathrm{p}_{\mathrm{si}}{ }^{0}=\mathrm{x}_{\mathrm{i}} \mathrm{p}_{\text {sati }}{ }^{0}$, for single-vapor isotherm contributions and for mixed adsorption potential contributions, respectively.

The IAST-D/R-Bering1-IAS combination seems to be easier to apply than the IASTD/R-Lewis-IAS, requiring fewer D/R equation calculations. After determining mole fractions $x_{i}$ of adsorbed mixture components by equating spreading pressures (Equation 13) of components and requiring that $\Sigma \mathrm{x}_{\mathrm{i}}=1$, one can calculate component i molar capacity (e.g., $\mathrm{mol} / \mathrm{g}$ ) by the Bering1-IAS combination: 


$$
n_{i}=x_{i} n_{T}=\frac{x_{i} W_{o}}{\Sigma x_{j} V_{m j}{ }^{0}} \exp \left[-\frac{R^{2} T^{2}}{E_{o}{ }^{2}}\left\{\frac{\Sigma x_{j} \ln \left(x_{j} p_{s a t j}{ }^{o} / p_{j}\right)}{\Sigma x_{j} \beta_{j}}\right\}^{2}\right]
$$

where the summation index $j$ includes $i, p_{j}$ is a component $j$ pressure (or concentration) in the vapor phase in equilibrium with the adsorbed mixture, $\mathrm{p}_{\text {satj }}{ }^{\circ}$ is a vapor pressure (or concentration) that would be in equilibrium with the bulk pure single component $j$ at the same temperature $T$, $\mathrm{V}_{\mathrm{mj}}{ }^{\mathrm{o}}$ is a pure component liquid molar volume, $\beta_{\mathrm{j}}$ is a pure component affinity coefficient, $\mathrm{E}_{\mathrm{o}}$ is the reference (benzene) adsorption energy of the activated carbon, and $\mathrm{W}_{0}$ is its micropore volume. The corresponding Lewis-IAS equation is:

$$
\left.n_{i}=x_{i} n_{T}=x_{i}\left[\sum_{j} \frac{x_{j}}{\frac{w_{o}}{V_{m j}{ }^{0}} \exp \left[-\left\{\frac{R T}{\beta_{j} E_{o}} \ln \left(\frac{x_{j} p_{s a t j}{ }^{0}}{p_{j}}\right)\right\}^{2}\right.}\right]\right]^{-1} \text {. }
$$

, where $j$ again includes $i$.

The results in Table 3 indicate that the Lewis and Molar Proportionality equations should not be used to calculate molar distributions from total molar adsorbed capacities. They are, however, useful for calculating total and component molar adsorbed capacities from molar distributions obtained experimentally or from separate calculations (Tables 2 and 4). 


\section{References}

[1] Wood GO. Reviews of models for adsorption of single vapors, mixtures of vapors, and vapors at high humidities on activated carbon for applications including predicting service lives of organic vapor respirator cartridges. Report LA-UR-00-1531. Los Alamos National Laboratory, Los Alamos, NM. 2000.

[2] Dubinin MM, Zaverina ED, Radushkevich LV. Sorption and structure of active carbons. I. Adsorption of organic vapors. Zh Fiz Khim 1947;21:1351-1362

[3] Stoeckli F. Dubinin's theory for the volume filling of micropores: An historical approach. Adsorp Sci Technol 1983:10:3-16

[4] Dubinin MM, Astakhov VA. Development of the concepts of volume filling of micropores in the adsorption of gases and vapors by microporous adsorbents. Izv Akad Nauk SSSR Ser Khim 1971:5-11

[5] Kisarov VM. A new equation for the adsorption isotherm. Russ J Phys Chem 1969;43(4):580-581. English translation from Zh Fiz Khim 1969;43:1037-1038

[6] Wood GO. Affinity coefficients of the Polanyi/Dubinin adsorption isotherm equations: A review with compilations and correlations. Carbon 2000; (Accepted for publication)

[7] Bering BP, Serpinskii VV, Surinova SI. Adsorption of a gas mixture. Communication 7. Joint adsorption of a binary mixture of vapors on activated charcoal. English translation from Izv Akad Nauk SSSR Ser Khim 1965;5:769-776

[8] Bering BP, Kabanova ON, Servinskii VV, Surinova SI, Yakubov TS. A new method of calculation of the adsorption of binary mixtures of vapors on microporous adsorbents. English translation from Izv Akad Nauk SSSR Ser Khim 1971;12:2641-2648 
[9] Xie Z, Guo D, Wu J, Yuan C. Adsorption equilibrium of vapor mixture on activated carbon. In Fundamentals of adsorption 6, Meunier F, ed. 1998;219-224 Elsevier, New York

[10] Lewis WK, Gilliland ER, Chertow B, Cadogan WP. Adsorption equilibria: Hydrocarbon gas mixtures. Ind Eng Chem 1950;42:1319-1326

[11] Lavanchy A, Stockli M, Wirz C, Stoeckli F. Binary adsorption of vapors in active carbons described by the Dubinin equation. Adsorp Sci Technol 1996;13:537-545

[12] Sundaram N. Equation for adsorption from gas mixtures. Langmuir 1995;11:3223-3234

[13] Polanyi M. Causes of forces of adsorption. Z Elektrochem 1920;26:370-374. Theories of adsorption of gases. General survey and some additional remarks. Trans Farad Soc $1932 ; 28: 316-333$

[14] Grant RJ, Manes M. Adsorption of binary hydrocarbon gas mixtures on activated carbon. I \& EC Fundamentals 1966;5:490-498

[15] Myers AL, Prausnitz JM. Thermodynamics of mixed-gas adsorption," A I Ch E J $1965 ; 11: 121-127$

[16] Lide DR, ed., CRC Handbook of Chemistry and Physics, $75^{\text {th }}$ Edition 1994;A-101, CRC Press, Inc., Boca Raton, FL

[17] Stoeckli F, Wintgens D, Lavanchy A, Stockli M. Binary adsorption of vapours in active carbons described by the combined gheories of Myers-Prausnitz and Dubinin (II). Adsorp Sci Technol 1997;15:677-683

[18] Lavanchy A, Stoeckli F. Dynamic adsorption, in active carbon beds, of vapour mixtures corresponding to miscible and immiscible liquids. Carbon 1999;37:315-321 
[19] Doong SJ, Yang RT. A simple potential-theory model for predicting mixed-gas adsorption. Ind Eng Chem Res 1988;27:630-635

[20] Doong SJ, Yang RT. Adsorption of mixtures of water vapor and hydrocarbons by activated carbon beds: Thermodynamic model for adsorption equilibrium and adsorber dynamics. AICHE Symposium Series 1987;83(259):87-97

[21] Lodewyckx P, Vansant EF. Influence of humidity on adsorption capacity from the Wheeler-Jonas model for prediction of breakthrough times of water immiscible organic vapors on activated carbon beds. Amer Ind Hyg Assoc J 1999;60:612-617

[22] Jonas LA, Sansone EB, Farris TS. Prediction of activated carbon performance for binary vapor mixtures. Am Ind Hyg Assoc J 1983;44:716-719

[23] Hoppe VH, Worch E. Zur berechnung des nichtidealen gemischadsorptionsgleichgewichtes benzen-isopropanol-activkohle B 4 unter verwendung experimentell bestimmter aktivitatskoeffizienten. $Z$ phys Chemie Leipzig 1982;6:1169-1177 
Table 1. Mixtures and $D / R$ parameters used for calculations

\begin{tabular}{|l|l|c|c|c|c|}
\hline \multicolumn{1}{|c|}{ Binary Mixture Components } & Carbon Designation & \multicolumn{2}{c|}{$\begin{array}{c}\text { Dubinin/Radushkevich Isotherm Parameters } \\
\text { (Benzene Reference) }\end{array}$} & $\begin{array}{c}\text { Data } \\
\text { Source }\end{array}$ \\
\hline & & $\begin{array}{c}\text { Micropore } \\
\text { Volume } \\
(\mathrm{cm} 3 / \mathrm{g})\end{array}$ & $\begin{array}{c}\text { Adsorption } \\
\text { Potential } \\
(\mathrm{kJ} / \mathrm{mol})\end{array}$ & $\begin{array}{c}\text { Affinity } \\
\text { Coefficients }\end{array}$ & $\begin{array}{c}\text { Ref } \\
\end{array}$ \\
\hline Chlorobenzene-Carbon Tetrachloride & Activated Carbon U-02 & 0.448 & 17.00 & $1.17,1.06$ & 11 \\
\hline Benzene-1,2-Dichloroethane & Activated Carbon U-02 & 0.448 & 17.00 & $1.00,0.91$ & 17 \\
\hline Benzene-Hexane & Carbon Mol Sieve J-1 & 0.469 & 18.70 & $1.00,1.28$ & 9 \\
\hline Benzene-Pentane & Carbon Mol Sieve J-1 & 0.469 & 18.70 & $1.00,1.11$ & 9 \\
\hline Hexane-Pentane & Carbon Mol Sieve J-1 & 0.469 & 18.70 & $1.28,1.11$ & 9 \\
\hline Benzene-Hexane & Activated Carbon GH-28 & 0.602 & 15.20 & $1.00,1.28$ & 9 \\
\hline Benzene-Pentane & Activated Carbon GH-28 & 0.602 & 15.20 & $1.00,1.11$ & 9 \\
\hline Hexane-Pentane & Activated Carbon GH-28 & 0.602 & 15.20 & $1.28,1.11$ & 9 \\
\hline Benzene-Isopropanol & Activated Carbon B-4 & 0.517 & 10.29 & $1.00,0.82$ & 23 \\
\hline
\end{tabular}


Table 2. Total Capacity of Mixtures Calculations: Models' Average Deviations (Accuracy) and Standard Deviations (Precision) from Experimental Values for 93 Binary Mixtures.

\begin{tabular}{|l|c|c|}
\hline \multicolumn{1}{|c|}{ Model and Option } & \multicolumn{2}{c|}{ Total Capacity (mmol/g) } \\
\hline & Average & Std Dev \\
\hline Volume Proportionality-SVI & -0.318 & 0.47 \\
\hline Volume Proportionality-IAS & 0.008 & 0.38 \\
\hline Volume Proportionality-IVS & -0.003 & 0.38 \\
\hline Molar Proportionality-SVI & -0.293 & 0.46 \\
\hline Molar Proportionality-IAS & 0.024 & 0.38 \\
\hline Molar Proportionality-IVS & 0.032 & 0.38 \\
\hline Lewis-SVI & -0.362 & 0.50 \\
\hline Lewis-IAS & -0.008 & 0.38 \\
\hline Lewis-IVS & -0.008 & 0.38 \\
\hline Bering1-SVI & -0.304 & 0.47 \\
\hline Bering1-IAS & -0.003 & 0.38 \\
\hline Bering1-IVS & -0.001 & 0.38 \\
\hline Bering2-SVI & -0.464 & 0.63 \\
\hline Bering2-IAS & 0.051 & 0.42 \\
\hline Bering2-IVS & 0.043 & 0.42 \\
\hline Molar Exclusion-SVI & 0.168 & 0.46 \\
\hline Molar Exclusion-IAS & 0.498 & 0.79 \\
\hline Molar Exclusion-IVS & 0.540 & 0.81 \\
\hline Volume Exclusion-SVI & 0.168 & 0.46 \\
\hline Volume Exclusion-IAS & 0.498 & 0.79 \\
\hline Volume Exclusion-IVS & 0.540 & 0.81 \\
\hline
\end{tabular}

SVI = Single Vapor Isotherm

IAS = Ideal Adsorbed Solution

IVS = Ideal Volumetric Solution 
Table 3. Molar Distribution Calculations: Models' Average Absolute Deviations (Accuracy) and Standard Deviations (Precision) of Component Calculated Mole Fractions from Experimental Values for One Selected Component of Each Binary Mixture.

\begin{tabular}{|l|c|c|c|}
\hline & $\begin{array}{c}\text { Average } \\
\text { Absolute } \\
\text { Value of } \\
\text { Residuals }\end{array}$ & $\begin{array}{c}\text { Standard } \\
\text { Deviation of } \\
\text { Residuals }\end{array}$ & $\begin{array}{c}\text { Number of } \\
\text { Mixtures that } \\
\text { Could be } \\
\text { Calculated }\end{array}$ \\
\hline Lewis-SVI & 0.659 & 0.267 & 31 \\
\hline Lewis-IAS & 0.664 & 0.338 & 43 \\
\hline Lewis-Total Pressure & 0.731 & 0.324 & 63 \\
\hline Molar Proportionality-SVI & 0.662 & 0.280 & 31 \\
\hline Molar Proportionality-IAS & 0.671 & 0.376 & 43 \\
\hline Molar Proportionality-Total Pressure & 0.803 & 0.383 & 63 \\
\hline Ideal Adsorbed Solution Theory & 0.054 & 0.071 & 93 \\
\hline Volumetric Adsorbed Solution Theory & 0.072 & 0.090 & 93 \\
\hline Polanyi Adsorption Potential Theory & 0.072 & 0.088 & 93 \\
\hline Molar Exclusion-SVI & 0.286 & 0.402 & 88 \\
\hline Molar Exclusion-IAS & 0.192 & 0.226 & 53 \\
\hline Molar Exclusion-IVS & 0.195 & 0.229 & 53 \\
\hline Volume Exclusion-SVI & 0.092 & 0.111 & 93 \\
\hline Volume Exclusion-IAS & 0.135 & 0.157 & 88 \\
\hline Volume Exclusion-IVS & 0.137 & 0.160 & 88 \\
\hline
\end{tabular}

SVI = Single Vapor Isotherm

IAS = Ideal Adsorbed Solution

IVS = Ideal Volumetric Solution 
Table 4. Combined Models' Average Deviations (Accuracies) and Standard Deviations (Precisions) of Calculated Component Capacities from Experimental Values for Both Components of 93 Binary Mixtures.

\begin{tabular}{|l|c|c|c|c|c|c|}
\hline \multicolumn{1}{|c|}{ Model and Option } & \multicolumn{2}{c|}{ IAST } & \multicolumn{2}{c|}{ VAST } & \multicolumn{2}{c|}{ Polanyi } \\
\hline & $\begin{array}{c}\text { Average } \\
\text { Deviation } \\
(\mathrm{mmol} / \mathrm{g})\end{array}$ & $\begin{array}{c}\text { Standard } \\
\text { Deviation } \\
(\mathrm{mmol})\end{array}$ & $\begin{array}{c}\text { Average } \\
\text { Deviation } \\
(\mathrm{mmol} / \mathrm{g})\end{array}$ & $\begin{array}{c}\text { Standard } \\
\text { Deviation } \\
(\mathrm{mmol} / \mathrm{g})\end{array}$ & $\begin{array}{c}\text { Average } \\
\text { Deviation } \\
(\mathrm{mmol} / \mathrm{g})\end{array}$ & $\begin{array}{c}\text { Standard } \\
\text { Deviation } \\
(\mathrm{mmol} / \mathrm{g})\end{array}$ \\
\hline Volume Proportionality -IAS & 0.0144 & 0.318 & 0.0408 & 0.497 & -0.0018 & 0.395 \\
\hline Volume Proportionality-IVS & 0.0150 & 0.318 & 0.0254 & 0.402 & -0.0176 & 0.449 \\
\hline Molar Proportionality-IAS & 0.0240 & 0.318 & 0.0362 & 0.407 & 0.0108 & 0.391 \\
\hline Molar Proportionality-IVS & 0.0288 & 0.320 & 0.0351 & 0.404 & 0.0143 & 0.391 \\
\hline Lewis-IAS & 0.0139 & 0.318 & 0.0236 & 0.402 & -0.0026 & 0.395 \\
\hline Lewis-IVS & 0.0146 & 0.318 & 0.0252 & 0.402 & -0.0026 & 0.396 \\
\hline Beringl-IAS & 0.0139 & 0.318 & 0.0244 & 0.402 & -0.0026 & 0.395 \\
\hline Bering1-IVS & 0.0147 & 0.318 & 0.0252 & 0.486 & -0.0018 & 0.395 \\
\hline Bering2-IAS & 0.0322 & 0.324 & 0.0464 & 0.408 & 0.0056 & 0.401 \\
\hline Bering2-IVS & 0.0286 & 0.325 & 0.0268 & 0.455 & 0.0018 & 0.403 \\
\hline
\end{tabular}

IAS = Ideal Adsorbed Solution

IVS $=$ Ideal Volumetric Solution 


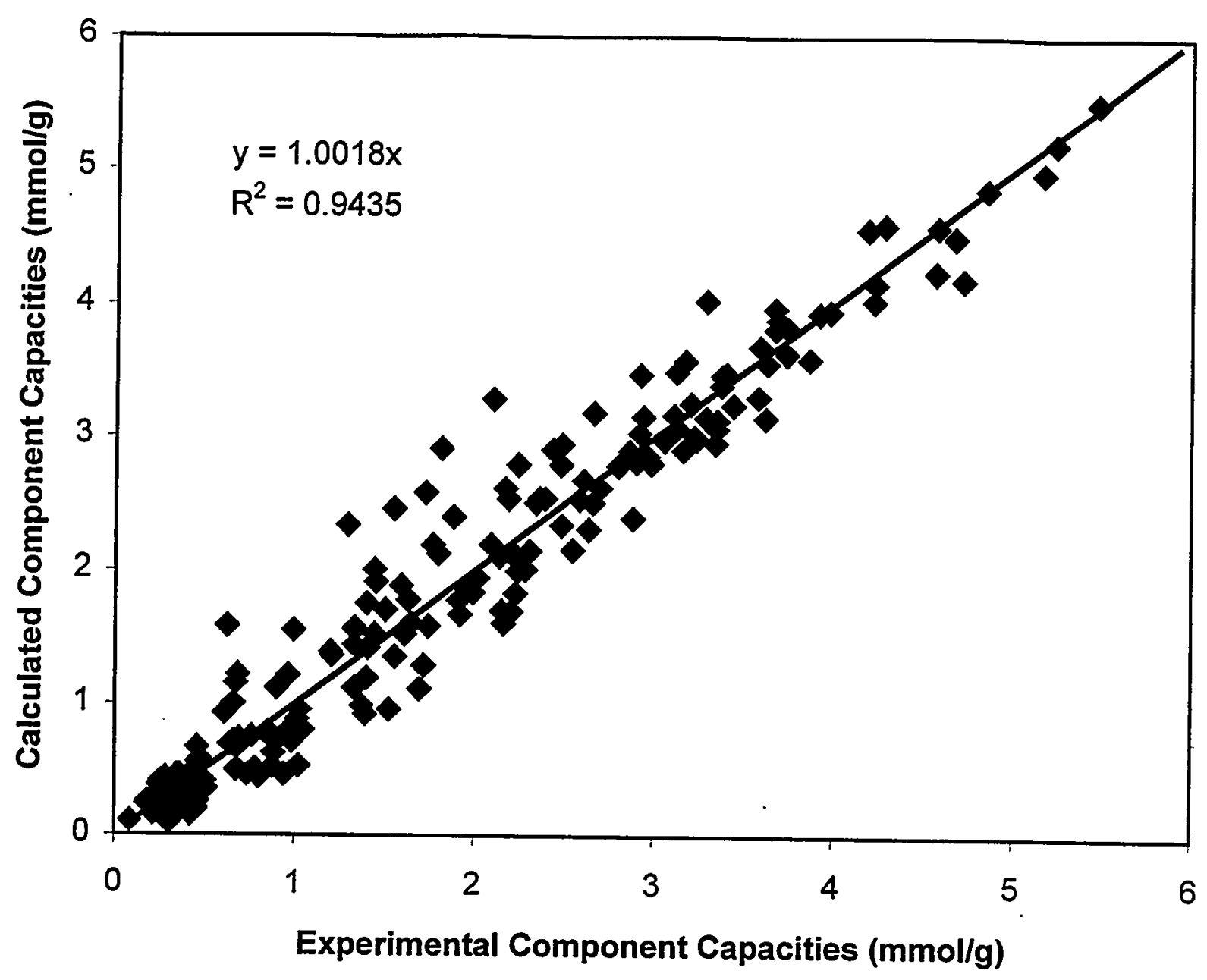

Fig. 1. Comparison of calculated and experimental capacities of 186 components of binary adsorbed mixtures using the IAST-D/R-Bering1-IAS combination of equations and options. The linear least squares slope (forced zero intercept) and squared correlation coefficient quantify average accuracy and precision, respectively. 